\title{
El acoso sexual en la administración pública como una manifestación de violencia laboral
}

\section{POR VERÓNICA ITATÍ GONZÁLEZ (*)}

Sumario: I. Introducción.- II. Acoso sexual: denominación.- III. Definiciones.- IV. Clases de acoso sexual (típico y ambiental).- V. Consecuencias para la Administración Pública.- VI. Resultados.- VII. Análisis de los resultados de las encuestas.- VIII. Conclusión.- IX. Bibliografía.

Resumen: en este artículo se presentan hallazgos de una investigación sobre el acoso sexual laboral en distintos organismos de la administración pública de la provincia de Corrientes. El objetivo de este trabajo es determinar la eficiencia y suficiencia de la normativa vigente en la provincia tendiente a disminuir y/o erradicar el acoso sexual en el empleo público. Para dar cuenta de este objetivo, se presenta y analiza los resultados de una encuesta.

Palabras claves: administración pública - acoso sexual - violencia laboral mujeres - discriminación

\section{Sexual harassment in the Public Administration as a manifestation of labor violence}

Abstract: this article presents findings of an investigation on labor sexual harassment in different bodies of the Public Administration of the Province of Corrientes. The objective of this work is to determine the efficiency and adequacy of the regulations in force in the province tending to reduce and / or eradicate sexual harassment in public employment. To account for this objective, the results of the aforementioned survey are presented and analyzed.

Keywords: public administration - sexual harassment - workplace - women - discrimination

(*) Prof. Adscripta a Derecho Administrativo I, Facultad de Derecho, Ciencias Sociales y Políticas, Universidad Nacional del Nordeste, UNNE. Becaria de Investigación de Iniciación, Secretaría General de Ciencia y Técnica, UNNE. 


\section{Introducción}

En el Primer Convenio Colectivo de Trabajo general para la Administración Pública Nacional Argentina, el acoso sexual fue contemplado como única modalidad de violencia laboral. Parte de la doctrina expresaba que no se estaba en presencia de mobbing en sentido estricto, ya que las causas y objetivos que pueden motivarlo son diferentes a los que se presentan en el acoso psicológico (Abajo Olivares, 2004; González de Rivera, 2005). No obstante, manifestaban estos autores que con relativa frecuencia incidentes de acoso sexual se transforman con posterioridad en supuestos de mobbing. Así, es bastante probable que un episodio de acoso sexual en el que el acosador ha visto frustrado su objetivo se transforme en un proceso posterior de hostigamiento y acoso laboral con todas las características del mobbing, de tal manera que el episodio de acoso sexual se convierte en el conflicto o disparador del ataque. Sobre todo, en aquellos casos en que la víctima no se atreve a denunciarlo o no tiene pruebas suficientes.

No caben dudas de que el acoso sexual constituye un hilo de continuidad de la violencia de género (Daza Bonachela y Martín Muñoz, 2012) y contribuye a mantener un orden de género basado en la discriminación.

Esto surge de la definición de violencia del artículo 4 de la ley No 26485 de Protección Integral para Prevenir, Sancionar y Erradicar la Violencia contra las Mujeres en los ámbitos en que desarrollen sus relaciones interpersonales, en la que se entiende por violencia contra las mujeres:

(...) toda conducta, acción u omisión, que de manera directa o indirecta, tanto en el ámbito público como en el privado, basada en una relación desigual de poder, afecte su vida, libertad, dignidad, integridad física, psicológica, sexual, económica o patrimonial, como así también su seguridad personal. Quedan comprendidas las perpetradas desde el Estado o por sus agentes. Se considera violencia indirecta, a los efectos de la presente ley, toda conducta, acción omisión, disposición, criterio o práctica discriminatoria que ponga a la mujer en desventaja con respecto al varón.

El acoso sexual, además de causar ofensa y/o humillación a quien la padece, puede convertirse en una condición de empleo o crear un ambiente de trabajo ofensivo que conculca el derecho de del trabajo y los derechos fundamentales de los trabajadores, trayendo aparejado la mayoría de las veces consecuencias nocivas para la salud de los mismos.

Una de las situaciones que contribuye a que la mujer que trabaja en el sector público se convierta en una víctima fácil de acoso sexual puede atribuirse 
principalmente a la falta de autonomía económica; es decir, cuando las sumas que perciba por su trabajado sea su único o principal ingreso, y la estructura jerarquizada que posee la administración pública, que la sitúa en una posición de sujeción y la obliga a acatar órdenes de su superior jerárquico, cuyo incumplimiento puede llevar muchas veces al despido directo.

Las mujeres son las principales víctimas de este flagelo. El hostigamiento o acoso sexual puede afectar a cualquier mujer, no interesa su edad, estado civil, apariencia física, nivel de estudios o estatuto profesional.

Sin perjuicio de lo expuesto, cabe mencionar que el acoso sexual no es un padecimiento que afecta solamente a las mujeres, ya que cada vez son más habituales y conocidos los casos de hombres víctimas de este flagelo. Sin embargo, las mujeres, dada su situación en el mercado laboral, son las más vulnerables a padecerlo, por múltiples razones que exceden el presente trabajo. Según el "Informe sobre Población Mundial 2000" de Naciones Unidas una de cada tres en el mundo ha padecido malos tratos o abusos. Esto también es válido para el acoso laboral en el empleo público, ya que, generalmente cuando se produce entre hombres, se llegan a situaciones límites que implican conductas agresivas. Sin embargo, entre mujeres la situación se prolonga en el tiempo y generalmente se recurre a mecanismos de evasión como solicitar licencia por enfermedad, pedir traslados o reubicaciones.

El objetivo general de este trabajo busca determinar la eficiencia y suficiencia de la normativa vigente tendiente a disminuir y/o erradicar el acoso sexual en el empleo público de la provincia de Corrientes.

La hipótesis preliminar que propondremos es que la normativa vigente en la provincia de Corrientes tendiente a combatir y/o erradicar el acoso sexual laboral en el sector público resulta insuficiente e ineficaz, habida cuenta del porcentaje de los casos detectados según la encuesta realizada.

La metodología que guía la investigación es fundamentalmente cuantitativa y cualitativa. Para recopilar y sistematizar la información se utilizaron fuentes primarias y secundarias.

Con los resultados obtenidos a través de la encuesta se pretende conocer cuál es la situación laboral actual en cuanto al acoso sexual en los distintos organismos de la administración pública de Corrientes y se pretende generar nuevos datos e hipótesis que constituyan materia prima para nuevas investigaciones y más profundas.

Respecto a las fuentes secundarias se revisó la correspondiente literatura sobre acoso sexual laboral, de autores extranjeros y nacionales. 


\section{Acoso sexual: denominación}

La expresión "acoso sexual" comenzó a divulgarse a partir del año 1975 en los Estados Unidos de América, en la versión inglesa de ella, es sexual harassment, que significa aquello.

Ahora bien, conforme a un diccionario de lengua inglesa(1), "harass" significa acosar, atosigar, hostigar, hostilizar y, según otro, quiere decir hacer repetidos ataques contra alguien (2). Conforme a lo dicho, se explica también por qué tal expresión es traducida al castellano como "hostigamiento sexual". En español, "acoso" es la acción y efecto de acosar, siendo esta última palabra, en la aceptación que entendemos corresponderle, perseguir, apremiar, importunar a una persona con molestias o requerimientos. Desde luego que también significa perseguir, sin darle tregua ni reposo, a un animal o una persona y, además, hacer correr al caballo (3).

En consecuencia, siendo "sexual", conforme tales diccionarios, lo relativo al sexo o a los sexos, el acople de ambas palabras puede entenderse que significa, en sumatoria, tanto como hostigar, hostilizar, atosigar, perseguir, apremiar, importunar a una persona con molestias o requerimientos sexuales. Con ello tenemos el concepto formal y general, pero como a nosotros lo que nos importa es el concepto de la expresión en las relaciones de trabajo, tendremos que agregar que tales o algunas de las circunstancias referidas se presenten en éste y que sean llevadas a cabo por el propio empleador, por quien lo represente, o por un superior jerárquico, porque, como afirma Crichton (1994) en su conocida novela sobre el tema el acoso sexual laboral es una cuestión de poder.

Finalmente, en concordancia con Rubinstein (1992) entendemos que la expresión "acoso sexual" es la que mejor refiere el concepto que pretendemos, más allá de análogos términos usados en otros países como "no querida intimidad". (Holanda), "molestia sexual" (Italia) o "chantaje sexual" (Francia).

\section{Definiciones}

Lograr expresar en una definición todos los contenidos y circunstancias que acompañan el acoso sexual es, sin duda, una tarea ímproba, sobre todo para acotar la conducta ilegal o prohibida, lo que ha generado una serie de definiciones que tal vez pudieran ser incompletas, pero que se integran las unas con las otras para conducir a un comprehensivo criterio final. De allí que vamos a transcribir a

(1) Ver Appteton's New Cayás Dictionary, p. 106.

(2) Horney - Gatenby - Wakefield, The advanced tearners Dictionary of Current English, p. 452.

(3) Real Academia Española, Diccionario de la Lengua Española, voces "acoso" y "acosar". 
continuación algunas de las definiciones que hemos hallado en nuestra investigación, para efectuar luego los consiguientes comentarios.

Parte de la doctrina dice que consiste en una "conducta verbal o física, cuyo autor sabe o debería saber que es ofensiva para la víctima". Agregan de inmediato, aclarando tales conceptos, que debe considerarse que la referida conducta física de naturaleza sexual debe ser indeseada y afirman que ésta se manifiesta en tocamientos, roces, frotamientos o pellizcos contra el cuerpo de un empleado para forzar o ejercer coerción, en procura de un intercambio sexual.

A su vez, Rubinstein (1992) afirma que

(...) la conducta verbal de naturaleza sexual se manifiesta con avances sexuales de tal carácter, que no son bien recibidos, o con proposiciones o presiones para obtener una actividad sexual, continuas sugestiones o invitaciones para concurrir o participar en actos sociales fuera del lugar de trabajo, flirteo ofensivo o sugestivas referencias o comentarios sobre conductas o actividades sexuales. Añade que este comportamiento se transforma en ilegal cuando el rechazo o la aceptación de tal conducta por la víctima sean utilizados o invocados como amenaza, para fundamentar una decisión que afecte a su empleo o condiciones de trabajo, lo que importa un ejercicio de poder al respecto, así como cuando la víctima entiende que la conducta sexual que atribuye haya ocasionado un perjuicio a su ambiente de trabajo (p. 10).

Otros lo definen diciendo que

El acoso sexual es una forma de abuso que incluye el hostigamiento reiterado y continuado de una persona con fines, métodos o motivaciones de naturaleza sexual, ejercido desde una posición de poder, físico, mental o jerárquico, generalmente en un contexto laboral, docente, doméstico o de cualquier otra índole que implique subordinación del acosado o acosada (González Rivera, 2005, p. 21)

Por su parte, Husbands (1993), dice que se trata de una exigencia formulada por un superior, que puede ser o no el propio empleador, de sexo masculino, a un subordinado suyo, de sexo femenino, para que se preste a una actividad sexual si quiere conseguir o conservar ciertos beneficios laborales, como, por ejemplo, un aumento de salario, un ascenso, un traslado o la permanencia en su puesto. De inmediato, llama a este supuesto 'acoso sexual por chantaje' y pasa a dar otra definición que se acomoda a otro supuesto. Conforme a ella, se trata de incitaciones sexuales importunas, de una solicitación sexual o de otras manifestaciones, verbales o físicas de índole sexual, con la finalidad o el efecto de coartar sin razón la actuación laboral de una persona o de cerrar un entorno de trabajo ofensivo, 
hostil, de intimidación o de abuso. En este caso, agrega, se trata de un acoso sexual por intimidación, que se diferencia del efectuado por chantaje, antes citado, en razón de que quien demanda no tiene que haber sufrido una pérdida económica importante, como haber sido despedida o no haber obtenido un ascenso o un aumento de salario. Este concepto se acerca más al que la doctrina española llama "acoso sexual ambiental".

Abajo Olivares (2004) entiende como acoso sexual a toda conducta verbal física, de naturaleza sexual, desarrollada en el ámbito de la organización y dirección de una empresa o institución, o en relación o como consecuencia de una relación de trabajo, realizada por un sujeto (generalmente varón, aunque esta característica no es excluyente) que sabe o debe saber que es ofensiva y no deseada por la víctima (generalmente mujer), determinando una situación que afecta al empleo y a las condiciones de trabajo, y/o creando un entorno laboral ofensivo, hostil, intimidatorio o humillante.

En Argentina, el decreto № 2385/93, que incriminó conductas de acoso sexual en el ámbito de la Administración Pública, describe al mismo como "el accionar del funcionario que con motivo o en ejercicio de sus funciones se aprovechare de una relación jerárquica induciendo a otro a acceder a sus requerimientos sexuales, haya o no acceso carnal" (artículo 1).

Rodríguez Saiach (1993) define el acoso sexual como:

El perseguir o importunar a un trabajador con fundamento en razones sexuales, persecución que tiene como fundamento el trabajo en relación de dependencia, bajo la dirección del empleador o personal jerárquico, situación que importa una discriminación en la comunidad laboral para el trabajador, que no acepta el asedio o el avance sexual, y que produce o puede producir a su respecto un cambio en las condiciones de trabajo, la cesantía o cualquier forma de menoscabo en su condición de ser humano y trabajador, importando a su vez una restricción a la libertad de elegir (p. 105).

En Australia la Sex Discrimination Act (1984) lo define como la actitud de una persona que produce un avance o requerimiento sexual a otra que no lo acepta o emplea respecto de la primera una conducta sexual de rechazo, si por ella misma puede entender razonablemente que esa conducta (el rechazo) le puede significar una desventaja en su empleo o trabajo, o puede dificultar su posibilidad de acceder a éste. En Canadá, el Código de Trabajo lo describe como toda conducta, comentario, gesto o contacto de naturaleza sexual que puede ser causa de agravio o de humillación para cualquier empleado, así como lo que razonablemente importe crear una condición de naturaleza sexual con relación al empleo, a su ejercicio 
o a una promoción. En Bélgica, el decreto real respectivo de 1992 lo define como "cualquier forma de comportamiento verbal, no verbal o física, de naturaleza sexual, que el acosador sabe, o debería saber, que es ofensivo para la dignidad de la mujer y del hombre en el trabajo" (4). A su vez, la ley francesa, también de 1992, lo conceptualiza como "un acto de un empleador o de un superior en la jerarquía laboral, por el cual éste, abusando de la autoridad que le da su posición, ejerce presión sobre un empleado o empleada, con el fin de obtener favores de índole sexual, para sí mismo o para un tercero.

Puede apreciarse la dispersión y la distinta amplitud de las definiciones descriptas, lo que puede tener una explicación en la circunstancia de que ellas son referidas al acoso sexual en sus respectivos países, y en éstos las legislaciones varían con relación a las situaciones contempladas. Por otra parte, ello señala diversas caracterizaciones de la conducta en análisis, algunas sumatorias y otras excluyentes y limitativas. Por lo pronto, diremos que el más generalizado concepto se refiere al acoso sexual llamado chantaje, al que los norteamericanos denominan quid pro quo (o sea, me das esto a cambio de eso), donde el ejercicio del poder o de la autoridad es un requisito necesario para tipificar la conducta como tal. Pero, además, algunas caracterizaciones se refieren a otros supuestos, en forma conjunta o excluyente, manifestados en conductas tales como calificativos sexistas, insinuaciones, tocamientos, invitaciones rechazadas y hasta la exhibición de material pornográfico, que tipifican un llamado acoso sexual ambiental o meramente por ambiente hostil.

Cabe destacar que

Este último comprende conductas como las referidas, tanto las asumidas por superiores como también por compañeros de trabajo. Efectuada esta aclaración, nos permitiremos llamar 'acoso sexual típico' al primero y 'acoso sexual ambiental' al último. Aquél es el concepto tradicional y estricto del acoso sexual, y al otro se lo designa como de intimidación (Husbands, 1993, p. 115).

\section{Clases de acoso sexual (típico y ambiental)}

Reiterando lo expuesto al considerar las definiciones, existen dos tipos, señalados y distintos, de acoso sexual que conviene precisar en el interés principal del conocimiento de la figura. Particularmente en sus manifestaciones normativas.

(4) Un resumen de su texto obra en la Revista Internacional del Trabajo (1993). vol. (112), № 1, p. 5. 
En un estudio del tema vinculado con el Ecuador y destacando la importancia del conocimiento de la figura, se determinó que la mujer sabe bien cuándo ha sido violada, pero no posee esa misma claridad respecto del hostigamiento sexual y tiene, por tanto, un cierto grado de incertidumbre para calificar ciertas actitudes de su empleador, de sus jefes o de sus compañeros y, en consecuencia, para determinar cuándo esa conducta constituye un asedio sexual, o sólo una manifestación amistosa a su respecto.

Por lo tanto:

Tiene un cierto recelo para su rechazo, hasta pensando, de alguna manera, si no es ella la responsable de la situación o de que así lo consideren, dada la tendencia general a imputar esta culpa a las mujeres. Este desconocimiento, o aun la diversidad de criterios al respecto, la inhiben de hacer un reclamo 'por vergüenza de verse implicada en un incidente sexual, el recelo que al protestar se centre la atención sobre su sexo y no sobre su trabajo, y la creencia de que nada se podrá hacer al respecto, que la torna vulnerable en su posición de denunciante' (Jaramillo, 1994, p. 6).

Pero este conocimiento es esencial también para los compañeros de trabajo, comprendidos, como dijimos, en uno de los tipos de acoso sexual, pues podrán adecuar sus conductas a términos que no infrinjan los límites que al respecto prevé la normativa, y acomodar las relaciones entre los sexos en el ambiente de trabajo, en forma de no incurrir en excesos que podrían hacer calificar sus conductas como reprobables o culpables.

Mayor aún es la importancia que tiene que el empleador, o su personal jerárquico, también conozcan el encuadre de estas figuras, para proceder en consecuencia o limitar su trato a lo relativo a las tareas, a la dirección o conducción que se les ha asignado, sin que la relación personal salga de esos límites, adoptando confianzas reprobables. Pero sabiendo que el poder que le confiere su función se limita a la exigencia de tareas propias del proceso productivo o de la actividad, y que no es lícito aprovechar tal circunstancia para efectuar proposiciones en su interés, que exceden el marco de la función y afectan la dignidad del subordinado. Al empleador, además, este conocimiento lo llevará a tener una actitud de control respecto de las conductas personales de sus jerárquicos y demás subordinados, en el medio donde se desarrollan las relaciones laborales, para evitar excesos, conductas discriminatorias y toda actitud que pueda interpretarse como agravio para quienes trabajan en tales circunstancias. Debe tener presente que el orden y el respeto en el medio laboral que dirige y coordina es su responsabilidad, sin que pueda al efecto alegar ajenidad, por ignorancia de lo que ocurre allí o de lo que hacen o exigen quienes lo representan. 


\section{IV.1. Típico}

Nos referimos aquí, al acoso sexual comúnmente llamado chantaje, al que la doctrina norteamericana denomina quid pro quo y al que se la señala como "tradicional" Husbands (1993). Este requiere siempre un ejercicio de poder o una relación desigual de poder. Es decir, necesita la actitud del propio empleador, o la de aquel en el que éste haya delegado sus tareas, pretendiendo imponer o imponiendo realmente una conducta de naturaleza sexual no desea, con amenazas que pueden afectar sus condiciones de trabajo o la continuidad en el empleo, agrediendo con ello su dignidad como ser humano. Es típicamente abuso de poder en este sentido, como lo reconoce la resolución sobre la protección de la dignidad del hombre y la mujer en el trabajo (Rubinstein, 1993, p. 5) que precisa el acoso sexual como "una no deseada conducta de naturaleza sexual que afecta la dignidad del hombre y la mujer en el trabajo". Se trata de un proceder que fuerza a un empleado, o a quien pretende serlo, a elegir entere acceder a la demanda impropia o perder su trabajo, desmejorar sus condiciones o quedar sin la posibilidad de obtener un empleo.

\section{IV.2. Ambiental}

Este otro concepto de acoso sexual se refiere a:

Una situación distinta, aquí no opera una manifestación de poder, sino que se trata de incitaciones o solicitaciones sexuales importunas, o bien de otras manifestaciones verbales, no verbales o físicas de naturaleza sexual, con la finalidad o el efecto de coartar sin razón la actuación laboral de una persona o de crear un entorno de trabajo ofensivo, hostil, de intimidación o de abuso, en muchos casos para lograr que abandone el empleo (Rubinstein, 1992, p. 5).

Tales manifestaciones pueden ser efectuadas por el empleador o sus agentes representativos, pero en este caso sólo persiguen el fin apuntado y no constituyen un acto de amenaza o de presión para conseguir favores de naturaleza sexual, en su interés o en el de terceros.

\section{Consecuencias para la administración pública}

Se ha determinado que el acoso sexual también afecta a la administración pública, lo que se refleja en las notas de ausentismo, menor productividad, cambios en el personal, y pedidos de traslados de un lugar de trabajo a otro. El sector público debería ser el ámbito donde se tiene que trabajar sin presiones, temores u otras circunstancias contraindicadas. 
En esa atmósfera, quedan afectadas las condiciones normales de trabajo, creando suspicacias, malos entendidos y una situación de virtual acecho, ante la posibilidad de sufrir asedios o tener que soportar conductas que afectan, humillan y lesionan la dignidad de las personas. Sin duda, ello convierte el lugar de trabajo en un ámbito donde la convivencia de los sexos resulte afectada, en desmedro de una buena relación, sin incurrir en desigualdades o discriminaciones.

No es posible trabajar adecuadamente, ni en las debidas condiciones, si la labor transcurre en ámbitos afectados por circunstancias adversas como las expuestas, ya que los resultados productivos guardaran relación con la tranquilidad y el respeto que debe existir en el lugar de trabajo. De allí surge el interés que debe tener la administración pública en evitar que se perturbe su ámbito, ejerciendo un adecuado control al respecto e inspirando confianza en su personal y creando reales posibilidades de prevención y reparo a tal efecto.

\section{Resultados}

A continuación se desarrollan los resultados de la recopilación y análisis de la normativa que sanciona el acoso sexual en el ámbito de la administración pública de Corrientes y de las encuestas realizadas al azar en distintos organismos de dicho ámbito.

\section{VI.1. Normativa vigente en sobre acoso sexual}

\section{VI.1.1. Constitución Nacional}

La Reforma constitucional de 1957 introdujo un artículo expresamente dedicado al trabajo que propicia la sanción de leyes que aseguren al trabajador determinados beneficios en el ejercicio de sus tareas. Se trata del artículo 14 bis que, en lo que a nosotros nos interesa, menciona expresamente la necesidad de que se le aseguren "condiciones dignas y equitativas de labor al trabajador". Cabe destacar que, se considera esta mención como "operativa"; por lo que tiene vigencia y exigibilidad por sí misma. La frase constitucional aludida asegura que "cualquier vínculo de trabajo debe ser respetuoso de la dignidad del trabajador, sin admitir, por tanto situaciones de hecho que pueden provocar algún desmedro físico o moral o atenten contra la calidad humana del trabajador" (Sagüés, 1982, p. 809). De allí concluimos que, dadas las circunstancias que acompañan el acoso sexual, según lo hemos tipificado, esta disposición de la Constitución Nacional es plenamente aplicable para entender que un hecho tal importa negar el principio mencionado de "condiciones dignas y equitativas de labor. 
En el mismo sentido, el trabajo como actividad humana, empeña la dignidad personal. Sin demasiadas disquisiciones filosóficas, es fácil comprender por qué se exige situar al hombre que trabaja, y a su actividad misma, en un ambiente decoroso, porque quien trabaja es una persona. La cláusula es amplia y comprende, entre otras obligaciones del empleador, el trato respetuoso.

Lo justo, lo decente, lo decoroso, lo adecuado, eso es lo que prescribe la norma, no sólo durante el tiempo de trabajo y en el lugar de trabajo, sino aún más allá, para asegurar, mediante las aludidas condiciones, la existencia digna de la persona humana (Bidart Campos, 1981, p. 492).

Compartimos absolutamente esta interpretación que, en su amplitud, condena todo tipo de acoso sexual, tanto el tradicional de chantaje, como el de intimidación o de ambiente hostil. Uniendo sus términos a lo expresado precedentemente por Sagüés (1982), en el sentido de que la cláusula es operativa, ella sería de plena aplicación en los supuestos referidos. Claro que se trataría de una normativa incompleta, ya que no señala las consecuencias de la conducta que afecta aquellas condiciones dignas, señaladas.

Pero también la Constitución reformada en 1994 nos proporciona otros elementos normativos para su aplicación, extensivamente, a los supuestos posibles de acoso sexual en las relaciones laborales. En efecto, el nuevo artículo 75, que reemplaza en su contenido al artículo 67 del texto anterior, se refiere a las facultades del Congreso Nacional. El inciso 22 del artículo 75, más allá de la facultad de aprobar o desechar Tratados concluidos con las demás Naciones y con las Organizaciones Internacionales, y aún conferir a éstos "jerarquía superior a las leyes", dispone que determinados Tratados y Convenciones tienen "jerarquía constitucional" y que debe entendérselos como complementarios de los derechos y garantías establecidos en su Primera Parte. Ahora bien, entre ellos se menciona a la Declaración Universal de Derechos Humanos y a la Convención sobre la Eliminación de todas las Formas de Discriminación Contra la Mujer. Con base en tales instrumentos, o en textos similares locales, se han basado los Estados que no regulan expresamente al acoso sexual, para incriminarlo y para sancionarlo.

También consideramos otra disposición constitucional, que se encuentra en el inciso 23 del artículo 75, referido a las facultades del Congreso Nacional. En dicha norma le confiere a éste la facultad de legislar y promover medidas de acción positiva, que garanticen la igualdad real de oportunidades y de trato y el pleno goce de los derechos reconocidos por ella y los Tratados Internacionales vigentes sobre Derechos Humanos respecto de las mujeres. Puede verse sin duda, en esta disposición la voluntad del Constituyente, de que el Congreso Nacional legisle expresamente sobre el acoso sexual, para garantizar de tal modo la igualdad real de oportunidades y de trato, así como el pleno goce de los derechos antes mencionados. 


\section{VI.1.2. Tratados internacionales sobre derechos humanos con jerarquía constitucional}

En primer lugar, haremos referencia a la Declaración Universal de Derechos Humanos, de 1948, la cual sería aplicable a los casos del acoso sexual según lo dispuesto en su artículo 23, donde se expresa que

a) Toda persona tiene derecho al trabajo, a la libre elección de su trabajo, a condiciones equitativas y satisfactorias de trabajo y a la protección contra el desempleo; b) Toda persona tiene derecho, sin discriminación alguna, a igual salario por trabajo igual; y c) Toda persona que trabaja tiene derecho a una remuneración equitativa y satisfactoria, que le asegure, así como a su familia, la existencia conforme a la dignidad humana.

Como vemos, sus expresiones permiten afirmar que nadie puede ser acosado sexualmente bajo la amenaza de perder el empleo, de no ingresar a él, de no tener condiciones dignas y equitativas de trabajo y hasta, en la mención a la protección contra el desempleo, considerándola más allá del eventual beneficio de la seguridad social, porque no es admisible que, por no acceder a los requerimientos de un acosador, pueda perderse el empleo. No sea admite, tampoco, una discriminación que afecte el salario, o el derecho a percibir una remuneración satisfactoria, para tener "una existencia conforme a la dignidad humana". En fin, ahora que se hallan plenamente vigentes estas normas, por disposición constitucional y con tal jerarquía, no se puede entrar ya a considerar si su mera ratificación les confirió tal alcance, y ahora puede directamente invocárselas para pretender que se considere lesiva al derecho a la dignidad de cada individuo una agresión como es el acoso sexual.

La Convención Interamericana de Belén do Pará constituye un instrumento internacional de carácter obligatorio (vinculante) para los Estados firmantes que la hayan incorporado a su ordenamiento interno (Argentina lo ha hecho a través de la ley No 24632 de 1996). En este marco, los Estados tienen, entre otros deberes, incluir en su legislación interna normas penales, civiles y administrativas, así como las de otra naturaleza que sean necesarias para prevenir, sancionar y erradicar la violencia contra la mujer y adoptar las medidas administrativas apropiadas que sean del caso (Capítulo III, "Deberes de los Estados", artículo 7, c). A partir de que la Asamblea General de la ONU en 1993 aprobó la Declaración para la Eliminación del Violencia contra la Mujer se empezó a reconocer que los Estados también son responsables de las violaciones a los derechos humanos contra ellas y que en consecuencia es un deber legislar en este sentido.

Reitero, la otra mención que nos atañe del artículo 75 -inciso 22- es la relativa a la Convención sobre la Eliminación de todas las formas de discriminación contra la Mujer, de 1979. Esta Convención, en su Preámbulo reconoce explícitamente 
que las mujeres siguen siendo objeto de importantes discriminaciones, que violan los principios de la igualdad de derechos y del respeto de la dignidad humana. Es propósito de esta Convención, ampliar la interpretación del concepto de los derechos humanos, mediante el reconocimiento formal de las limitaciones que respecto de la mujer provienen de ciertas manifestaciones de la cultura y de la tradición. Se afirma en una introducción que éstas se manifiestan en estereotipos, hábitos y normas que originan las múltiples limitaciones jurídicas, políticas y económicas que se aprecian en la sociedad respecto de la mujer. Por eso, el Preámbulo de la Convención destaca que para lograr la plena igualdad entre el hombre y la mujer, es necesario modificar el papel tradicional tanto del hombre como de la mujer en la sociedad y en la familia. Para ello, exige que los patrones socioculturales de conducta de hombres y mujeres, para eliminar "los prejuicios y las prácticas consuetudinarias y de cualquier otra índole que estén basados en la idea de la inferioridad o superioridad de cualquiera de los sexos o en funciones estereotipadas de hombres y mujeres" (artículo 5º, "a").

Su Artículo 2, en su parte pertinente expresamente determina que

Los Estados partes condenan la discriminación contra la mujer en todas sus formas, convienen en seguir, por todos los medios apropiados y sin dilaciones, una política encaminada a eliminar la discriminación contra la mujer y, con tal objeto, se comprometen a:

a) Adoptar medidas adecuadas, legislativas y de otro carácter, con las sanciones correspondientes, que prohíban toda discriminación contra la mujer.

b) Establecer la protección jurídica de los derechos de la mujer sobre una base de igualdad con los del hombre y garantizar, por conducto de los tribunales nacionales o competentes y de otras instituciones públicas, la protección de la mujer contra todo acto de discriminación.

e) Tomar todas las medidas apropiadas para eliminar la discriminación contra la mujer practicada por cualesquiera personas, organizaciones o empresas.

Por su parte, el Artículo 5 determina que

Los Estados partes tomarán todas las medidas apropiadas para:

a) Modificar los patrones socioculturales de conductas de hombres y mujeres con miras a alcanzar la eliminación de los prejuicios y las prácticas consuetudinarias y de cualquier otra índole que estén basados en la idea de la inferioridad o superioridad de cualquiera de los sexos o en funciones estereotipadas de hombres y mujeres. 
Por último, su Artículo 11 expresamente establece que

Los Estados partes adoptarán todas las medidas apropiadas para eliminar la discriminación contra la mujer en la esfera del empleo con el fin de asegurar, en condiciones de igualdad entre hombres y mujeres, los mismos derechos, en particular:

a) El derecho al trabajo como derecho inalienable de todo ser humano.

b) El derecho a las mismas oportunidades de empleo, inclusive a la aplicación de los mismos criterios de selección en cuestiones de empleo.

c) El derecho a elegir libremente profesión y empleo, el derecho al ascenso a la estabilidad en el empleo y a todas las prestaciones y otras condiciones de servicio, y el derecho al acceso a la formación profesional y al readiestramiento, incluido el aprendizaje, la formación profesional superior y el adiestramiento periódico.

De todo lo expuesto se concluye que no pueden caber dudas de que el Congreso Nacional debe dictar (por lo que la Nación asumió este compromiso en los foros internacionales y aquél lo ratificó) las normas protectorias antes descriptas, entre ellas, una legislación específica o bien modificatoria de la legislación laboral o, tal vez, ampliatoria de ésta para incorporar como figura autónoma al acoso sexual.

\section{VI.1.3. Ley contra la discriminación No 23.592}

Los términos de esta ley imponen conductas y establecen sanciones para quienes arbitrariamente impidan, obstruyan, restrinjan, o de algún modo menoscaben el pleno ejercicio, sobre bases igualitarias, de los derechos y garantías fundamentales reconocidos por la Constitución Nacional (artículo 1, párrafo 1). En lo atinente al acoso sexual, ellos son los señalados precedentemente, tanto los tendientes a garantizar la dignidad en el trabajo, como los destinados a condenar toda discriminación, o intento de ésta, y a reconocer los derechos de la mujer.

Esta ley permite, a pedido del damnificado, requerir que se deje "sin efecto el acto discriminatorio o cesar en su realización y a reparar el daño moral y material ocasionados" (artículo 1, párrafo 1). La amplitud de estas normas debe destacarse en nuestra materia, particularmente en cuento expresamente prevén la posibilidad de suprimir el acto lesivo, como lo pretendemos, sin necesidad de considerarse despedido, y comprometer uno de los bienes más valiosos en este tiempo, como es el empleo. 
El artículo 1, donde se inserta el texto referido, se complementa con un párrafo 2 en el que se expresa que "se considerarán particularmente los actos u omisiones discriminatorios determinados", entre otros motivos, por razón de sexo. En los artículos siguientes eleva la pena de todo delito, reprimido por el Código Penal o leyes complementarias, cuando sea cometido por razones raciales, de nacionalidad, religiosos o de ideas políticas.

\section{VI.1.4. Constitución de la provincia de Corrientes}

El artículo 16 de la Constitución de la Provincia de Corrientes expresamente establece que: "Todos los funcionarios y empleados públicos son responsables en los casos y forma establecidos en esta constitución y las leyes".

Asimismo, el actual artículo 28 de la Constitución de la provincia de Corrientes, reza:

La administración pública provincial está regida por los principios de legalidad, eficacia, austeridad, congruencia normativa, desconcentración operativa, capacidad, imparcialidad, equidad, igualdad y publicidad de las normas y actos. Su actuación tiende a lograr economía, sencillez e informalismo en el trámite, celeridad, participación y el debido procedimiento público para los administrados. Los funcionarios y empleados públicos deben ajustar su actuación a dichos principios. Ningún funcionario público debe ejercer violencia laboral sobre los empleados a su cargo o bajo su dependencia. La violación de este precepto constituye falta grave.

Por último, cabe mencionar que el Artículo 45 del mismo cuerpo legal, en su parte pertinente establece que

El Estado garantiza la igualdad real de oportunidades para mujeres y varones en lo cultural, económico, laboral, político, social y familiar; incorpora la perspectiva de género en el diseño y ejecución de las políticas públicas y estimula la modificación de los patrones socio culturales con el objeto de eliminar prácticas basadas en el prejuicio de superioridad de cualquiera de los géneros.

\section{VI.1.5. Ley Provincial de Ética Pública No 5.911/09}

Ley provincial de Ética Pública № 5911/09, en su artículo 16, 6º establece pautas de conducta para los funcionarios de todos los poderes públicos en orden a evitar el fenómeno indeseado del acoso laboral, expresando como prohibición: 
Ejercer cualquier tipo de coacción entre otros, el acoso sexual, entendiéndose por tal el accionar del funcionario que con motivo o en ejercicio de sus funciones se aprovechase de una relación jerárquica induciendo a otro a acceder a sus requerimientos sexuales, haya o no acceso carnal. Las denuncias o acciones que corresponda ejercer con motivo de la configuración de la conducta antes descripta podrán ejercitarse conforme el procedimiento general o, a opción del agente, ante el responsable del área de la jurisdicción respectiva.

\section{VI.1.6. Ley Provincial No 5.903}

En el 2009 se dictó la ley No 5.903 a través de la cual la provincia de Corrientes se adhería a la Ley Nacional No 26.485 de Protección Integral para Prevenir, Sancionar y Erradicar la Violencia contra las Mujeres en los ámbitos en que desarrollen sus relaciones interpersonales (artículo 1).

Esta Ley nacional tiene por objeto promover y garantizar:

a) La eliminación de la discriminación entre mujeres y varones en todos los órdenes de la vida; b) El derecho de las mujeres a vivir una vida sin violencia; c) Las condiciones aptas para sensibilizar y prevenir, sancionar y erradicar la discriminación y la violencia contra las mujeres en cualquiera de sus manifestaciones y ámbitos; d) El desarrollo de políticas públicas de carácter interinstitucional sobre violencia contra las mujeres; e) La remoción de patrones socioculturales que promueven y sostienen la desigualdad de género y las relaciones de poder sobre las mujeres; f) El acceso a la justicia de las mujeres que padecen violencia; $y, g)$ La asistencia integral a las mujeres que padecen violencia en las áreas estatales y privadas que realicen actividades programáticas destinadas a las mujeres y/o en los servicios especializados de violencia.

Esta norma garantiza todos los derechos reconocidos por la Convención para la Eliminación de todas las Formas de Discriminación contra la Mujer, por la Convención Interamericana para Prevenir, Sancionar y Erradicar la Violencia contra la Mujer, por la Convención sobre los Derechos de los Niños y por la ley No 26.061 de Protección Integral de los derechos de las Niñas, Niños y Adolescentes.

Su Artículo 4 define violencia contra las mujeres como:

toda conducta, acción u omisión, que, de manera directa o indirecta, tanto en el ámbito público como en el privado, basada en una relación desigual de poder, afecte su vida, libertad, dignidad, integridad física, psicológica, sexual, económica o patrimonial, como así también 
su seguridad personal. Quedan comprendidas las perpetradas desde el Estado o por sus agentes. Asimismo, considera violencia indirecta a toda conducta, acción omisión, disposición, criterio o práctica discriminatoria que ponga a la mujer en desventaja con respecto al varón.

Quedan comprendidos en dicha definición los siguientes tipos de violencia contra la mujer: física, psicológica, sexual, económica y patrimonial, y simbólica (artículo 5).

Su Artículo sexto define a la violencia laboral contra las mujeres diciendo que es:

Aquella que discrimina a las mujeres en los ámbitos de trabajo públicos o privados y que obstaculiza su acceso al empleo, contratación, ascenso, estabilidad o permanencia en el mismo, exigiendo requisitos sobre estado civil, maternidad, edad, apariencia física o la realización de test de embarazo. Constituye también violencia contra las mujeres en el ámbito laboral quebrantar el derecho de igual remuneración por igual tarea o función. Asimismo, incluye el hostigamiento psicológico en forma sistemática sobre una determinada trabajadora con el fin de lograr su exclusión laboral.

\section{Análisis de los resultados de las encuestas}

Reitero, se realizaron encuestas semiestructuradas a trabajadoras de distintos organismos de la administración pública de la provincia de Corrientes elegidos al azar.

De esta manera se visitaron los siguientes Organismos Estatales: a) Ministerio de Industria, Trabajo y Comercio de Corrientes; b) Subsecretaría de Trabajo; c) Ministerio de Educación; d) Ministerio de Desarrollo Social; e) Ministerio de Justicia y Derechos Humanos; f) Consejo General de Educación; g) Ministerio de Seguridad.

El cuestionario fue aplicado a una muestra no probabilística de un total de 97 mujeres, entre los 18 a 45 años de edad.

Para la elección de la muestra se consideró que las mujeres a encuestarse debían encontrase trabajando en el organismo que se interesaba estudiar, y en virtud de la sensibilidad por el tema a tocar se utilizaron cuestionarios anónimos para que la trabajadora se sintiera con libertad de poner su percepción sin sentir que fuera a ser identificada, agregándose, además, una sección de observaciones.

A través del presente estudio se ha detectado que fueron quince mujeres quienes manifestaron haberlo sufrido. Es decir, más del quince por ciento de las 
encuestadas padecieron este flagelo. De ese porcentaje la edad de las víctimas varió entre los 18 a 36 años, por lo que se puede concluir que las mujeres más jóvenes fueron las más afectadas. De esto podemos influir que las mujeres cuando son más jóvenes son más propensas a sufrir acoso sexual en su trabajo, aunque no tengamos el fundamento del porque es así, y dicho interrogante excede el presente trabajo. Tal vez, una razón podría ser que son más vulnerables en razón de su edad o poca experiencia, o bien que en razón de ello no serían capaces de realizar la correspondiente denuncia.

\section{Gráfico No 1}

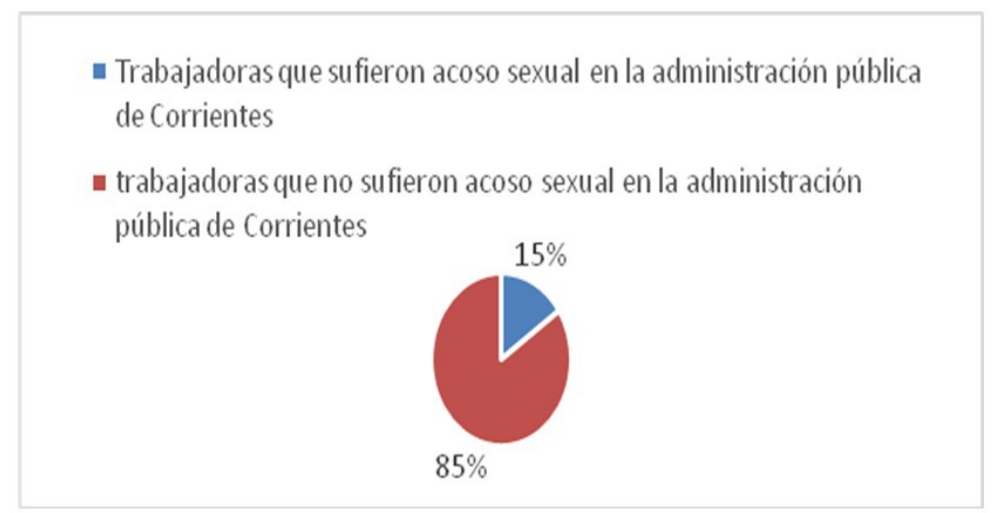

Fuente: resultados de encuestas realizadas a distintos organismos estatales de la provincia de Corrientes.

Además, se verificó de la encuesta que en la mayoría de los casos el acoso sexual provino de los superiores jerárquicos de las víctimas, y que en la mayoría de los casos los acosadores fueron hombres. Es decir, que la expresión de mobbing que más apareció era el descendente, el cual es el más común de todos. Cabe mencionar que fueron doce las trabajadoras que manifestaron que los acosadores eran sus superiores jerárquicos (mobbing típico) y catorce de ellas que provenía la violencia de los hombres. Es decir, hubo tres casos de mobbing horizontal y un solo caso de acoso que provino de una mujer que resultó ser su compañera de oficina. Estos datos se verán reflejados en los gráficos que se realizan seguidamente. 


\section{Gráfico No 2}

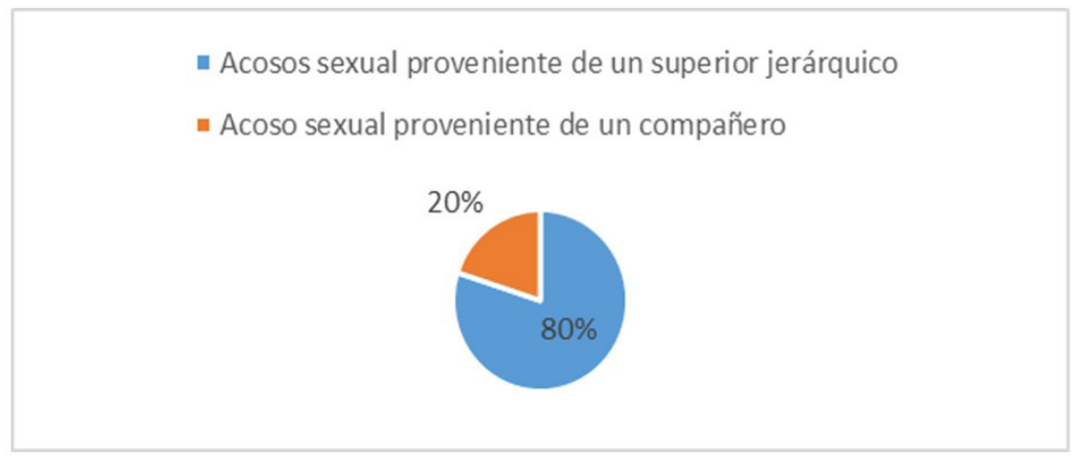

Fuente: resultados de encuestas realizadas a distintos organismos estatales de la provincia de Corrientes.

\section{Gráfico No 3}

- Acosadorhombre - Acosadoramujer

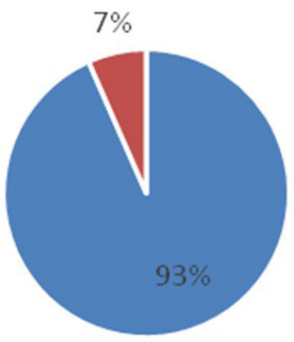

Fuente: resultados de encuestas realizadas a distintos organismos estatales de la provincia de Corrientes. 
Del total de las encuestadas que manifestaron haber sufrido acoso sexual en el ámbito público, cabe resaltar que ninguna de ellas hizo la correspondiente denuncia, tomando como fundamento una serie de factores que seguidamente se describen:

Siete de ellas expresaron que carecían de pruebas para realizar una denuncia, por lo que se veían frustradas al no poder demostrar la existencia del acoso. Esto demuestra las deficiencias de parte de los organismos públicos en esta temática, en lo referente a la información, capacitación y prevención que debería efectuarse al respecto.

Tres mujeres manifestaron tener miedo a dañar su propia reputación (básicamente, ante el temor de ser culpabilizadas del acoso, lo que una vez más demuestra las deficiencias que venimos remarcando). Una de ellas manifestó tener miedo a ser ridiculizada (una denuncia "prematura" puede hacer que pierda credibilidad, o que parezca una exageración sin fundamento).

Cuatro de ellas expresaron que temían a las posibles represalias que pudieran tomar en su contra los acosadores dado que eran sus superiores jerárquicos quienes las acosaban.

Las conductas que se manifestaron fueron: chistes, piropos, conversaciones de contenido sexual, miradas, muecas, etc., llamadas telefónicas, presiones para salir o invitaciones con intenciones sexuales, "roces" o contactos físicos con clara connotación sexual.

Por último, cinco (5) mujeres expresaron que no conocían las herramientas legales con las que contaban, además de tener un escaso conocimiento de lo que era el acoso sexual laboral.

\section{Conclusión}

Como quedó evidenciado en esta investigación a pesar de contar la Provincia de Corrientes con numerosas normativas legales que sancionan el acoso sexual laboral en el empleo público, existen numerosos casos de este flagelo en dicho ámbito.

Asimismo, se confirmó la hipótesis inicial planteada, en la que se aducía que la normativa legal vigente en la provincia tendiente a combatir y/o erradicar el acoso sexual laboral en el sector público resultaron ser insuficientes e ineficaces.

El acoso sexual representa un grave problema que debe ser atendido, debido que importa un atentado de carácter psicofísico para la víctima, lesionando su 
dignidad y el debido respeto que ésta merece, y puede generar, además, consecuencias lesivas, de carácter laboral, psicológico y económico. Estas consecuencias, por consiguiente, estarían afectando a la administración pública de Corrientes, lo que no puede ni debe ser tolerado en un verdadero estado de derecho

Por esta razón, resulta primordial y necesario que se adopte una política preventiva en la materia, por medio de la cual se difundan sus características, circunstancias y promuevan las correspondientes medidas preventivas.

Se debe abordar la temática a través de una mayor prevención, lo que se logra a través de una mayor difusión del problema, que bien podría lograrse por medio de propagandas, talleres y jornadas de capacitación, entre otros, buscando así que los trabajadores tomen conocimiento de cuando están en presencia de una situación de acoso sexual en su ámbito laboral y de cuáles son los derechos que le asisten.

Además, los organismos estatales deben contar con instrumentos administrativos eficaces para que rápidamente tomen curso las denuncias, investigación y sanciones. También, deben ofrecer asesorías legales que pueda disipar todo tipo de dudas al respecto, y debe evaluarse periódicamente y con mucho cuidado y dedicación, el perfil psicológico de los que ejercen funciones jerárquicas.

Por otro lado, en el ámbito gremial, se debe promover espacios de intercambios interdisciplinarios de experiencias, para evaluar las alternativas de acción y la eficacia de las medidas implementadas, como así también, facilitar una comunicación fluida (informativa y formativa) sobre esta temática, entre quienes participan en la vida interna de la asociación sindical, y quienes lo hacen dentro del organismo.

\section{Bibliografía}

Abajo Olivares, F. J. (2004). Mobbing. Acoso psicológico en el ámbito laboral. Buenos Aires: Depalma.

Bidart Campos, G. (1981). Principios constitucionales de derecho del trabajo (individual y colectivo) y de la seguridad social en el artículo 14 bis. Buenos Aires: Ediar.

Crichton, M. (1994). El acoso. Buenos Aires: Emecé.

Daza Bonachela, M. y Martín Muñoz, A., (2012). Las medidas disuasorias frente al acoso sexual y por razón de género. Madrid: Dykinson.

González de Rivera, J. (2005). El maltrato psicológico. Madrid: S. L. U. Espasa Libros. 
Husbands, R. (1993). Revista internacional del Trabajo, vol. (112), № 1. Ginebra.

Jaramillo, T. (1994). El hostigamiento sexual en las relaciones laborales. Jornada Iberoamericana y del Caribe. San Juan de Puerto Rico.

Rodríguez Saiach, L. (1993). Acoso sexual, hurtos y otras causas de despido. Buenos Aires: Alcotán.

Rubinstein, M. (1992). Dealing with sexual horassment at work: the experience of industrialized countries. OIT Conditions of work digest. Combating sexual harassment, vol. (11), (p. 10).

Sagüés, N. (1982). Constitucionalismo Social. En Vázquez Vialard (dir.), Tratado de derecho del trabajo, vol. (II). Buenos Aires: Astrea.

Palomino, T. (1993). Hostigamiento sexual. La mujer en el trabajo. Lima: Juris Laboral.

\section{Legislación}

Ley No 26485. Boletín Oficial de la República Argentina, Buenos Aires, 14/04/2009.

Ley No 23592. Boletín Oficial de la República Argentina, Buenos Aires, 05/09/1988.

Ley No 5911. Boletín Oficial de la provincia de Corrientes, 04/11/2009.

Ley Provincial No 5903. Boletín Oficial de la provincia de Corrientes, 25/11/2009.

Constitución de la provincia de Corrientes. Boletín Oficial de la provincia de Corrientes, 13/06/2007.

Fecha de recepción: 28-03-2019

Fecha de aceptación: 24-09-2019 